\title{
Dinamika Pemberdayaan Kelembagaan Komunitas Petani Dalam Mewujudkan Ketahanan Pangan Pedesaan di Kabupaten Buru
}

\author{
Idrus Hentihu, Samsia Umasugi, Abdul Latif Wabula, Said Abdurahman Assagaf, Abdi Wael, Rosita Umanailo, Hamiru Hamiru, \\ Mansyur Nawawi, Sukainap Pulhehe, Mirja Ohoibor, Riki Bugis, Edi Said Ningkeula SP, Muhammad Bula, Lutfi Rumkel, Iskandar \\ Hamid, Irma Magfirah, Siami Prafitriyani, Belinda Sam, Wa Malmia, Syaiful Rachman, Salma Yusuf, M Yusran Zakaria, \\ Universitas Iqra Buru \\ chairulbasrun@gmail.com
}

\begin{abstract}
Abstrak
Penelitian ini memiliki tujuan pokok untuk mengkaji dinamika dan peran kelembagaan ketahanan pangan komunitas petani di pedesaan dalam upaya mewujudkan ketahanan pangan yang berkelanjutan, dengan berbasiskan pada keragaman aspek sosiologis dan ekologis. Sedangkan tujuan spesifik dari penelitian ini adalah untuk : (1) Mengidentifikasi peta sosial dan sumber-sumber kehidupan (human capital, social capital, natural capital, phisycal capital, financial capital) komunitas desa, (2) Mengidentifikasi proses kebijakan dan hasil implementasi program pemberdayaan masyarakat dalam mewujudkan ketahanan pangan komunitas desa, (3) Mengidentifikasi peran dan menganalisis tingkat partisipasi kelembagaan lokal, intervensi pemerintah dan swasta dalam mewujudkan ketahanan pangan komunitas desa, (4) Menganalisis dinamika kelembagaan dan aktor (masyarakat, pemerintah, swasta, dan perguruan tinggi) dalam mengakses dan memanfaatkan sumber-sumber kehidupan di tingkat lokal untuk mewujudkan ketahanan pangan komunitas desa. Peneliti secara mengambil dua lokasi penelitian pada tipologi komunitas petani yang berbeda (komunitas petani pesisir dan pegunungan). Diharapkan hasil dari penelitian ini dapat pula membandingkan persamaan dan perbedaan dalam proses dinamika pemberdayaan kelembagaan komunitas petani pesisir dan pegunungan dalam upaya mewujudkan ketahanan pangan komunitas pedesaan. Pengumpulan data dilakukan dengan metode wawancara mendalam (indepth interview), diskusi kelompok terarah (focus grup discussion), penelusuran sejarah hidup (life history), pengamatan berpartisipasi (participant observation), studi arsip, dokumen dan studi pustaka. Sedangkan metode analisis yang digunakan adalah model analisis siklus interaktif antara data yang terkumpul, pereduksian data, penampilan data dan penarikan kesimpulan. Agar penarikan kesimpulan memiliki validitas data yang kebenarannya dapat diyakini dan diuji, maka peneliti menggunakan teknik triangulasi sumber data dan metode.
\end{abstract}

Keyword: pemberdayaan masyarakat, dinamika pemberdayaan, komunitas petani pesisir dan pegunungan

Pangan adalah kebutuhan dasar manusia paling utama, dan pemenuhan kebutuhan akan pangan merupakan bagian dari hak asasi setiap individu (DKP 2014; Handewi, Rachman dan Ariani, 2014). Ketahanan pangan, disamping sebagai prasyarat untuk memenuhi hak asasi pangan masyarakat, juga merupakan pilar bagi eksistensi dan kedaulatan sebuah bangsa. Mengingat pentingnya masalah pangan, maka setiap negara akan menempatkan pembangunan di bidang ketahanan pangan sebagai pondasi 
bagi pembangunan di bidang lainnya. Bangsa Indonesia meskipun dikenal sebagai negara agraris, namun pada kenyataannya masih menghadapi masalah ketahanan pangan yang sangat serius. Masalah yang tengah dihadapi ini, tidak hanya terbatas pada sub-sistem produksi, melainkan juga pada subsistem distribusi dan sub-sistem konsumsi (Handewi, Rachman dan Ariani, 2014; Widayanti dan Sanjawati 2013; Dumasari 2015).

Permasalahan-permasalahan yang dihadapi dalam upaya mewujudkan ketahanan pangan memiliki dimensi yang luas dan beragam (Handewi, Rachman dan Ariani, 2014). Masalah ketahanan pangan dapat dikaji dari dimensi sosial, ekonomi, budaya, politik dan ekologi. Apabila ketahanan pangan dipandang sebagai sebuah sistem, maka masalah ketahanan pangan dapat dikaji dari subsistem persediaan, sub-sistem distribusi dan sub-sistem konsumsi. Selain itu masalah ketahanan pangan juga dapat ditinjau dari aspek manajemen yakni berkaitan dengan efektifitas penyelenggaraan fungsi-fungsi perencanaan, pelaksanaan, pengawasan, pengendalian serta kordinasi dari berbagai kebijakan dan program (Dharmawan dan Kinseng, 2013). Mengingat luasnya dimensi permasalahan yang dihadapi dalam mewujudkan ketahanan pangan, maka penelitian ini difokuskan pada aspek dinamika pemberdayaan kelembagaan pangan di tingkat komunitas dan desa.

Masalah ketahanan pangan di Indonesia pada dasarnya terkait erat dengan masalah kemiskinan di pedesaan (Dharmawan dan Kinseng, 2013). Diketahui bahwa sebagian besar penduduk miskin itu berada di pedesaan, dan pada umumnya mereka adalah petani gurem (skala kecil) dan buruh tani. Tentunya kondisi ini sangat ironis jika dikaitkan dengan fakta lain yang menunjukan bahwa sebagian besar produksi pangan di Indonesia diadakan oleh para petani gurem dengan kepemilikan lahan kurang dari 0,5 ha dan buruh tani. Di satu sisi para petani gurem dan buruh tani adalah produsen pangan terbesar di negeri ini, namun disisi lain mereka juga adalah kelompok terbesar yang tergolong miskin dan rentan terhadap masalah kerawanan pangan (Widayant B dan Sanjawati ND. 2013; Astuti RD dan Hanani N. 2012).

Kondisi ini menunjukan kemungkinan terjadinya kesalahan dalam kebijakan pembangunan pertanian yang cenderung mengutamakan aspek produktivitas dan efisiensi, namun belum memberikan perhatian yang cukup bagi upaya pemberdayaan dan peningkatan kesejahteraan para petaninya, bahkan yang terjadi adalah ketidakberdayaan petani (Sumarti, 2007; Prawoto, 2012). Upaya pemberdayaan dan peningkatan kesejahteraan petani itu sendiri akan membutuhkan adanya sebuah kelembagaan sebagai pintu masuk (Soetomo 2013). Melalui wadah kelembagaan (kelembagaan lokal) itulah setiap pihak yang berkepentingan dapat berdialog, belajar dan bekerja bersama untuk mengkaji permasalahanpermasalahan yang dihadapi dan sekaligus mencari alternatif jalan keluarnya (Nasdian, 2016).

Namun kelembagaan lokal tersebut menjadi melemah, memudar dan bahkan hancur karena digerus oleh pendekatan pembangunan masa lalu yang berciri terpusat, seragam dan mendominasi. Mengacu kepada keseluruhan uraian ini, maka dipandang perlu untuk mengkaji lebih mendalam mengenai dinamika pemberdayaan kelembagaan pada komunitas petani dengan karakateristik sosial, budaya, ekonomi, politik dan ekologi yang beragam dalam upaya mewujudkan ketahanan pangan masyarakat pedesaan.

Terdapat beragam definisi mengenai petani, hal ini disebabkan karena kata petani itu sendiri memiliki dimensi makna yang luas (sosial, budaya, ekonomi dan politik). Seperti halnya Scoot, memandang 
bahwa petani adalah orang yang bercocoktanam (melakukan budidaya) di lahan pertanian. Sementara Wolf mendefinisikan petani sebagai segolongan orang yang memiliki sekaligus menggarap lahan pertanian dimana hasil produks pertaniannya digunakan untuk memenuhi kebutuhan sendiri dan bukan untuk dijual (Dharmawan dan Kinseng, 2013).

Terkait dengan penelitian ini, peneliti menggunakan konsep sebagaimana konsep Marzali (1999) tentang petani, yang penekanannya lebih kepada proses perkembangan tingkat sosio-kultural masyarakat. Dimana petani dicirikan melalui tiga aspek yaitu karakteristik perkembangan masyarakat, lokasi (tempat menetap), dan tipe produksi. Pertama, secara umum petani berada diantara masyarakat primitif dan modern, Kedua, petani adalah masyarakat yang hidup menetap di dalam komunitas pedesaan, dan Ketiga, ditinjau dari tipe produksi dan orientasi usahataninya, maka petani berada dalam posisi transisi antara petani primitif dan petani modern (farmer).

Konsep di atas, mengacu pada konsep Redfield tentang peasant. Perbedaan utamanya terletak pada aspek penggunaan tenaga kerja dan orientasi hasil usahataninya. Dimana petani pedesaan di Indonesia pada umumnya tidak lagi sepenuhnya menggunakan tenaga kerja keluarga, melainkan untuk jenis-jenis pekerjaan tertentu, mereka juga memanfaatkan tenaga kerja dari luar keluarganya (buruh tani). Demikian pula dari orientasi hasil usahataninya, produksi petani tidak lagi semata-mata hanya diorientasikan untuk memenuhi kebutuhan pangan keluarga, melainkan juga untuk memperoleh keuntungan ekonomi (semi-komersil).

Kelembagaan yang ada di dalam suatu masyarakat pada hakikatnya memiliki tujuan untuk mengatur agar suatu sistem sosial dapat sedemikian rupa bekerja sesuai dengan apa yang diharapkan oleh anggota masyarakat tersebut (Soekanto, 1999; Uphof, 1992). Demikian pula halnya dengan lembaga pangan yang ada pada komunitas pedesaan pada dasarnya dibangun dengan tujuan untuk mengatur sistem pangan (sub-sistem produksi, distribusi dan konsumsi) agar sedemikian rupa bekerja sesuai dengan nilai-nilai serta konsensus yang telah disepakati bersama.

Fokus penelitian ini adalah mengkaji dinamika pemberdayaan kelembagaan komunitas pedesaan dalam mewujudkan ketahanan pangan yang berkelanjutan (sustainable food scurity) dengan berbasis pada keragaman sosiologis dan ekologis. Penulis dalam penelitian ini menggunakan tiga pendekatan utama yaitu : (1) pendekatan "sustainable rural livelihood" dari Chambers dan Conway (Dharmawan dan Kinseng, 2013), (2) pendekatan dan konsep "entitlement" dari Amartya Sen (Dharmawan dan Kinseng, 2013), serta (3) kerangka pendekatan dari Nasdian (2016) tentang pemberdayaan partisipatif komunitas pedesaan berbasis pengembangan dan penguatan kapasitas, jejaring kerjasama (networking), dan sinergy antar stakeholders (masyarakat, pemerintah dan swasta).

Pemilihan kerangka teori tersebut di atas didasarkan pada pemikiran bahwa pemberdayaan kelembagaan pangan dalam upaya mewujudkan ketahanan pangan omunitas petani pedesaan bukanlah merupakan proses yang sederhana dan statis, melainkan bersifat kompleks dan dinamis, sebagai hasil dari dinamila pola interaksi antara sistem sosial dengan sistem ekologi. Secara sederhana, kerangka kerja ini menggambarkan manusia sebagai individu dan kelompok, merupakan penggerak berbagai sumber-sumber kehidupan (human capital, social capital, natural capital, physical capital dan financial capital) dan kebijakan untuk memenuhi kebutuhan hidup dan mengatasi berbagai masalah dan ancaman, demi tercapainya suatu penghidupan yang berkelanjutan (Dharmawan dan Kinseng, 2013). 
Pertimbangan lain dari pemilihan kerangka teori di atas adalah adanya fakta-fakta bahwa proses implementasi program-program pemberdayaan kelembagaan komunitas petani di pedesaan kerapkali dihadapkan pada beberapa kendala diantaranya : (1) kurangnya pelibatan (partisipasi) masyarakat pedesaan (terutama lapisan bawah) dalam setiap tahapan kegiatan (perencanaan, pelaksanaan, dan evaluasi), (2) lemahnya kapasitas kelembagaan komunitas di pedesaan, (3) lemahnya jejaring kerjasama (networking), dan (4) masih kurangnya upaya-upaya untuk mengoptimalkan sinergy atau positive sum antar para pemangku kepentingan (stakeholders).

Konsep pemberdayaan lahir dari analisis bahwa adanya pihak yang tidak berdaya (powerless) berhadapan dengan pihak lain yang berkuasa (powerfull), pada akhirnya cenderung menimbulkan pola hubungan yang bersifat eksploitatif, dominasi dan penindasan (Widayanti 2012). Karena itu untuk membantu pihak yang tidak berdaya, perlu adanya suatu proses pembagian (sharing) dan juga peralihan (transfer) sumber-sumber daya (ekonomi, sosial, budaya dan politik) diantara pihak-pihak pemangku kepentingan (stakeholders) secara adil. Sehingga pada akhirnya terjadi sebuah proses perubahan pola hubungan antara pihak-pihak yang berkepentingan, dari pola hubungan subyek - obyek menjadi hubungan subyek - subyek. Hal ini sejalan dengan apa yang dikemukakan oleh Soetomo (2013) yang menyimpulkan bahwa pemberdayaan pada dasarnya adalah upaya menjadikan suasana kemanusiaan yang adil dan beradab menjadi semakin efektif secara struktural, baik dalam kehidupan keluarga, masyarakat, negara, regional, internasional dalam bidang politik, ekonomi dan lain-lain.

Undang-Undang No.7 Tahun 1996 tentang pangan memberikan definisi tentang ketahanan pangan sebagai : kondisi terpenuhinya pangan bagi rumah tangga yang tercermin dari tersedianya pangan yang cukup, baik jumlah maupun mutunya, aman, merata dan terjangkau. Ketahanan pangan dapat dicapai apabila telah terbangunnya suatu tata kelembagaan nasional pangan yang kokoh, yaitu segala sesuatu yang berhubungan dengan struktur dan proses pengaturan, pembinaan, dan atau pengawasan terhadap kegiatan atau proses produksi, distribusi dan konsumsi.

Dharmawan dan Kinseng (2006) menyatakan bahwa dalam wacana akademik terdapat tiga konsep ketahanan pangan yang dapat saling dipertukarkan yaitu ; (1) ketahanan pangan, (2) kemandirian pangan, dan (3) kedaulatan pangan. Konsep ketahanan pangan berkaitan dengan beberapa konsep turunannya, yaitu kemandirian pangan yang diartikan sebagai kapasitas suatu kawasan untuk memenuhi kebutuhan pangannya secara swasembada. Sedangkan konsep kedaulatan pangan menunjuk pada kemandirian pangan juga melibatkan beberapa variabel tambahan di bidang sosioproduksi dan sosiopolitis dari sebuah sistem pangan di suatu wilayah.

Berdasarkan pada keseluruhan uraian di atas, dapat disimpulkan bahwa konsep dan dimensi ketahanan pangan bersifat luas dan kompleks, sehingga pilihan atas kebijakan dan program yang akan diambil guna memecahkan permasalahan pangan di suatu wilayah, tergantung pada kondisi dan karakteristik sosial, ekonomi, budaya, politik dan ekologi yang ada di wilayah tersebut. Hal ini juga mengandung arti bahwa terdapat keragaman potensi dan masalah pangan, antara satu wilayah dengan wilayah lainnya. Sehingga kebijakan dan program ketahanan pangan yang akan disusun, tidak dapat diseragamkan untuk seluruh wilayah, melainkan harus berlandaskan pada keragaman dan sekaligus keunikan potensi dan masalah pangan yang ada di masing-masing wilayah. Pertimbangan ini menjadi lebih relevan mengingat bahwa 
bangsa Indonesia adalah bangsa yang memiliki tingkat keragaman yang tinggi dari berbagai aspek kehidupan (sosial, ekonomi, budaya, politik dan ekologi).

\section{Referensi}

Astuti RD dan Hanani N. 2012. Peran Kelembagaan Lokal dalam Pengembangan Deversifikasi Pangan. Jurnal Habitat. Volume 20 Nomor 2. Hal 90-97.

Creswell J W. 2009. Research Design. Qualitatif, Quantitative, and Mixed Methods Approaches. Third Edition. Sage Publications. Thousand Oaks California 91320. Terjemahan.Yogyakarta (ID): Pustaka Pelajar

Dewan Ketahanan Pangan (DKP). 2014. Kebijakan Umum Ketahanan Pangan 2010-2014. Dewan Ketahanan Pangan. Jakarta.

Dharmawan, A. H. dan Rilus Kinseng. 2013. Aspek Sosial-Budaya dalam Rekrontruksi Kelembagaan Sosial Penanganan dan Pencegahan Rawan Pangan dan Gizi Buruk. Prosiding Lokakarya Nasional II Penganekaragaman Pangan. Forum Kinerja Pengakeragaman Pangan. Bogor.

Dumasari. 2015. Meningkatkan Fungsi Lembaga Lokal untuk Pengembangan Desa Mandiri Pangan. Jurnal Agritech. Volume 10 Nomor 1. Hal 60-70

Hadi AP. 2015. Tinjauan Terhadap Berbagai Program Pemberdayaa Masyarakat di Indonesia. Jurnal Ekonomi Pembangunan Volume 4 Nomor 7. Hal. 71-82.

Hamid, I. (2010). Identifikasi gulma pada areal pertanaman cengkeh Eugenia aromatica) di Desa Nalbessy Kecamatan Leksula Kabupaten Buru Selatan. Agrikan: Jurnal Agribisnis Perikanan, 3(1), 62-71.

Handewi, P.S. Rachman dan Mewa Ariani. 2014. Ketahanan Pangan : Konsep, Pengukuran dan Strategi. FAE. Vol 20. No.1. Hal 54-59

Hentihu, Idrus (2007) Analisisi Pemasaran Tanaman Nilam (Pogostemon cablin Benth)( Studi Kasus Desa Pamotan Kecamatan Dampit Kabupaten Malang ). Other thesis, University of Muhammadiyah Malang. diakses tanggal 15 Agustus 2018.

Magfirah, I. (2017). Efektivitas Model Pembelajaran Discovery dengan Setting Kooperatif Ditinjau dari Kemampuan Analogi dan Generalisasi Matematis Siswa Kelas VII MTs Al-Fakhriyah Makassar (Doctoral dissertation, Universitas Negeri Makassar).

Magfirah, I., Rahman, U., \& Sulasteri, S. (2015). Pengaruh Konsep Diri Dan Kebiasaan Belajar Terhadap Hasil Belajar Matematika Siswa Kelas Viii Smp Negeri 6 Bontomatene Kepulauan Selayar. MaPan: Jurnal Matematika dan Pembelajaran, 3(1), 103116.

Miles dan Huberman.1992. Analisis Data Kualitatif : Buku Sumber Tentang Metode-Metode Baru. Penerbit Universitas Indonesia (UI-Press). Jakarta.

Nasdian, F. Tonny. 2016. Pengembangan Masyarakat. Yayasan Obor Indonesia. Jakarta

Nawawi, M., \& Agus Sudaryanto, S. H. (2009). Perkawinan adat sasi dan akibatnya terhadap hukum kekerabatan adat di Desa Debowae Kecamatan Waeapo Kabupaten Buru (Doctoral dissertation, Universitas Gadjah Mada).

Ningkeula, E. S. (2015). Analisis karakteristik metereologi dan morfologis DAS Wai Samal Kecamatan Seram Utara Timur Kobi Kabupaten Maluku Tengah. Agrikan: Jurnal Agribisnis Perikanan, 8(2), 81-91.

Ningkeula, E. S. (2016). Analisis karakteristik morfometri dan hidrologi sebagai ciri karakteristik biogeofisik DAS Wai Samal Kecamatan Seram Utara Timur Kobi Kabupaten Maluku Tengah. Agrikan: Jurnal Agribisnis Perikanan, 9(2), 76-86.

Prawoto N. 2012. Model Pengembangan dan Pemberdayaan Masyarakat Berbasis Kemandirian untuk Mewujudkan Ketahanan Ekonomi dan Ketahanan Pangan di Jawa Tengah. Jurnal Organisasi dan Manajemen Volume 8 Nomor 2. Hal 135-154

Pulhehe, S. (2001). Tinjauan PP Nomor 10 Tahun 1983 Menurut Hukum Islam (Perkawinan-Perceraian) (Doctoral dissertation, Universitas Airlangga).

Purwaningsi Y. 2016. Ketahanan Pangan: Situasi, Permasalahan, Kebijakan dan Pemberdayaan Masyarakat. Jurnal Ekonomi Pembangunan. Volume 5 Nomor 9. Hal 23-28

Redfield, R. 1985. Masyarakat Petani dan Kebudayaan. Rajawali. Jakarta.

Soetomo. 2013. Pemberdayaan Masyarakat. Mungkinkah Muncul Antitesisnya. Pustaka Pelajar. Yogyakarta

Sumarti, Titik. 2007. Model Pemberdayaan Petani dalam Mewujudkan Desa Mandiri dan Sejahtera : Kajian Kebijakan dan Sosial Ekonomi tentang Ketahanan Pangan pada Komunitas Desa Rawan Pangan di Jawa. Sekretariat Badan Penelitian dan Pengembangan Pertanian. 
Umanailo, M Chairul Basrun . 2017. “Marginalisasi Buruh Tani Akibat Alih Fungsi Lahan." OSF. December 11. doi:10.17605/OSF.IO/9CZK2.

Umanailo, M Chairul Basrun. (2019). Strategi Bertahan Hidup Petani Padi Gogo Di Pulau Buru Survival Strategies Of The Upland Rice Farmers In Buru Island. Jurnal Ekonomi Pertanian dan Agribisnis, 3 (1);50-58..

Umanailo, M Chairul Basrun. 2017. "Kajian dan Analisis Sosiologi." OSF. December 11. doi:10.17605/OSF.IO/PV24F.

Umanailo, M Chairul Basrun. 2017. "Masyarakat Buru Dalam Perspektif Kontemporer." OSF. December 10. doi:10.17605/OSF.IO/KZGX3.

Umanailo, M Chairul Basrun. 2018. "IImu Sosial Budaya Dasar.” OSF. March 17. doi:10.17605/OSF.IO/4HPWC.

Umanailo, Rosita (2009) Studi Tentang Struktur Dan Komposisi Hutan Pantai Sendang Biru Malang Selatan. Other Thesis, University Of Muhammadiyah Malang. http://eprints.umm.ac.id/11153/ diakses tanggal 15 Agustus 2018.

Umanailo, Rosita (2013) Implementasi Kebijakan Perum Perhutani Dalam Pengelolaan Sumberdaya Hutan Bersama Masyarakat Sekitar Hutan (Studi Di Wilayah Perum Perhutani Kph Malang). Masters thesis, University of Muhammadiyah Malang. http://eprints.umm.ac.id/30546/ diakses tanggal 15 Agustus 2018.

Uniqbu, Pusat S P d P, Abdul L Wabula, Said A Assagaf, Abdi Wael, Idrus Hentihu, Rosita Umanailo, Hamiru, et al. 2018. "Gerakan Bupolo Magrib Mengaji Sebagai Media Aktualisasi Pruralisme." OSF. October 6. doi:10.17605/OSF.IO/FDZ3N.

Uniqbu, Pusat S P d P, Belinda Sam, Lutfi Rumkel, Abdi Wael, Idrus Hentihu, Rosita Umanailo, Hamiru, et al. 2018. "Feminisme Perempuan Adat Di Pulau Buru." OSF. October 7. osf.io/j9r8u.

Uniqbu, Pusat S P d P, Edi S Ningkeula, Belinda Sam, Lutfi Rumkel, Abdi Wael, Idrus Hentihu, Samsia Umasugi, et al. 2018. "Daya Dukung Kawasan Pedesaan Di Pesisir Barat Pulau Buru Untuk Pengembangan Wisata Bahari." OSF. October 7. doi:10.17605/OSF.IO/MYFS6.

Uniqbu, Pusat S P d P, M Y Zakaria, Salma Yusuf, Syaiful Rachman, Wa Malmia, Belinda Sam, Abdul L Wabula, et al. 2018. “Gerakan Buru Membaca Sebagai Media Pembelajaran Masyarakat Di Kabupaten Buru." OSF. October 7. doi:10.17605/OSF.IO/NECH5.

Widayant B dan Sanjawati ND. 2013. Peran Kelembagaan Rumahtangga di Perdesaan dalam Perubahan Pola Konsumsi Pangan Lokal Untuk Ketahanan Pangan di Jogyakarta. Prosiding Seminar Nasional Fakultas Agroindustri Universitas Mercu Buana. Jogyakarta. Hal 39-45

Widayanti S. 2012. Pemberdayaan Masyarakat: Pendekatan Teoritis. Jakarta: Jurnal Kesejahteraan Sosial Volume 1 Nomor 1.

Witoro. 2013. Menemukan Kembali dan Memperkuat Sistem Pangan Lokal. Makalah Lokakarya Forum Pendamping Petani Regio Gedepahala, Kampung Pending, Sukabumi.

Yin RK. 2008. Studi Kasus (Desain dan Metode). PT. Raja Grafindo Persada. Jakarta.

Zakaria, M. Y. (2017). Karakteristik Penyelesaian Masalah Matematika ditinjau dari Kecenderungan Kepribadian Pada Siswa kelas X SMA Negeri 16 Makassar (Doctoral dissertation, Pascasarjana). 